\title{
Serum Albumin Modulates the Bioactivity of Rosmarinic Acid
}

\author{
AU1 Elsa Brito, André Silva, ${ }^{1}$ Pedro Luis Vieira Falé, ${ }^{1-3}$ Rita Pacheco, ${ }^{1,3,4}$ António Serralheiro, \\ Parvez I. Haris, ${ }^{6}$ Lia Ascensão, and Maria Luísa Serralheiro ${ }^{1-3}$ \\ AU2 $>{ }^{1}$ Centro de Química e Bioquímica, Faculdade de Ciências, Universidade de Lisboa, Campo Grande, Portugal. \\ ${ }^{2}$ Departamento de Química e Bioquímica, Faculdade de Ciências, Universidade de Lisboa, Campo Grande, Portugal. \\ AU3 ${ }^{3}$ BioISI-Biosystems and Integrative Sciences Institute, Faculdade de Ciências, Universidade de Lisboa, Campo Grande, Portugal. \\ ${ }^{4}$ Área Departamental de Engenharia Química, Instituto Superior de Engenharia de Lisboa, Lisboa, Portugal. \\ ${ }^{5}$ INESC and CINAMIL, Academia Militar, Lisboa, Portugal. \\ ${ }^{6}$ Faculty of Health and Life Sciences, De Montfort University, Leicester, United Kingdom. \\ ${ }^{7}$ Centro de Estudos do Ambiente e do Mar, Faculdade de Ciências, Universidade de Lisboa, Campo Grande, Portugal.
}

\begin{abstract}
Rosmarinic acid (RA) is a phenolic compound with biological activity. The objective of the present study was to investigate whether this compound kept its biological activity in the presence of proteins. For this purpose, bovine serum albumin (BSA) was used as a model protein, and the capacity of the RA to inhibit acetylcholinesterase (AChE) and affect antioxidant activity was evaluated in the absence and presence of BSA. A mixture of phenolic compounds containing RA, obtained from a medicinal plant was added to this study. The AChE inhibitory activity of RA was reduced by $\sim 57 \%$ in the presence of BSA, while the antioxidant activity increased. These results lead to the investigation of the effect of RA on the BSA structure using Fourier transform infrared spectroscopy (FTIR). At $37^{\circ} \mathrm{C}$ and higher temperatures, RA caused a decrease in the temperature modifications on the protein structure. Furthermore, FTIR and native-gel analysis revealed that protein aggregation/ precipitation, induced by temperature, was reduced in the presence of RA. The novelty of the present work resides in the study of the enzyme inhibitory activity and antioxidant capacity of polyphenols, such as RA, in the presence of a protein. The findings highlight the need to consider the presence of proteins when assessing biological activities of polyphenols in vitro and that enzyme inhibitory activity may be decreased, while the antioxidant capacity remains or even increases.
\end{abstract}

KEYWORDS: • acetylcholinesterase $\bullet$ antioxidant activity $\bullet$ FTIR $\bullet$ protein secondary structure $\bullet$ SDS-PAGE

\section{AU6}

AU7

$\mathbf{P}$ OLYPHENOLIC COMPOUNDS ARE bioactive secondary plant metabolites that have diverse biological functions. ${ }^{1}$ Rosmarinic acid (RA) is present in several infusions from medicinal plants, mainly those from the Lamiaceae family. ${ }^{2}$ Infusions of medicinal herbs contain several phenolic compounds ${ }^{2,3}$ that may, in part, justify their reported ethnopharmacological activity. The presence of phenolic compounds in infusions from Plectranthus barbatus Andrews were previously determined as having acetylcholinesterase (AChE) inhibitory activity as well as antioxidant activity. ${ }^{4} \mathrm{RA}$ is one of the phenolic compounds responsible for AChE inhibitory effect detected in the Lamiaceae polar extracts. ${ }^{4,5}$ Since AChE is an enzyme associated with cholinergic neurotransmission, its inhibition is used to alleviate symptoms in Alzheimer's disease, gastrointestinal disorders,

Manuscript received 20 June 2017. Revision accepted 2 January 2017. and other illnesses. ${ }^{6}$ It was also demonstrated by Fourier transform infrared spectroscopy (FTIR) that polyphenolic compounds interact with human albumin and lysozyme, ${ }^{7}$ which are plasma transporter proteins. Such fact could explain how these phenolic acids were found in the plasma and also detected in the brain of lar ory animals where they can inhibit AChE activity. ${ }^{8}$ Serum albumins (SAs), the most abundant transporter proteins in the plasma of vertebrates are characterized by having several binding sites for numerous metabolites in the polypeptide chains and, due to these multiple binding properties, SAs present wide clinical, pharmacological, and biochemical applications. ${ }^{9,10}$ SAs are heart-shaped proteins that comprise three helical domains, each one with two subdomains. The helical content of SAs was determined to be around $70 \%$, and comparative analysis, using X-ray crystallography and immunological studies, revealed that there are structural homologies between different organisms. ${ }^{10}$ To study, protein secondary structure FTIR spectroscopy can be used. It is a valuable tool to detect structural changes and interactions between proteins and small molecules. ${ }^{11,12}$ The vibrational spectra of proteins in the mid-infrared region generate spectral signatures, such as 
the amide I (1700-1600 $\left.\mathrm{cm}^{-1}\right)$ and the amide II (1600$1500 \mathrm{~cm}^{-1}$ ) bands, mostly associated to vibrations in the peptide bond region. ${ }^{13-15}$ These bands are sensitive not only to protein structures, mainly $\alpha$-helix and $\beta$-sheets, but also give information about interactions through band shifts and width changes. ${ }^{11}$ The X-ray structure of bovine serum albumin (BSA) has been determined and has been shown to contain a predominantly helical structure and the absence $\beta$-sheet structure. ${ }^{10}$ Using FTIR spectroscopy, BSA was identified as being composed of $67 \% \alpha$-helix structure, $10 \%$ of $\beta$-turn, around $23 \%$ of extended chain, and no $\beta$-sheet structure is detected. ${ }^{16}$

Expanding upon our previous work on interaction between herbal infusion compounds and proteins, ${ }^{7}$ the aim of the present study was to evaluate whether the biological activities demonstrated by RA and the herbal (P. barbatus) decoction rich in RA, would be modulated by the presence of proteins.

\section{MATERIALS AND METHODS}

\section{Chemicals}

All chemicals were of analytical grade DPPH (2,2diphenyl-1-picrylhydrazyl), tris (hydroxymethyl) amino methane, AChE (E.C.3.1.1.7) type VI-S, from electric eel $349 \mathrm{U} / \mathrm{mg}$ protein, 5,5'-dithiobis[2-nitrobenzoic acid] (DTNB), acetylthiocholine (AChI), BSA fraction $\mathrm{V}$, glycine, ammonium persulfate, trypan blue, and RA were obtained from Sigma (Barcelona, Spain). Potassium dihydrogen phosphate, acetic acid glacial, and bromophenol blue were obtained from Merck (Darmstadt, Germany); potassium chloride from Fluka (Switzerland); and sodium chloride and disodium hydrogen phosphate anhydrous from Panreac (Barcelona, Spain). Acryl/Bis 29:1 were obtained from Amresco (Solon, OH, USA) and $\mathrm{N}, \mathrm{N}, \mathrm{N}^{\prime} \mathrm{N}^{\prime}$-tetramethylethylenediamine (TEMED). Methanol obtained from Merck (VWR International, Darmstadt, Germany) and glycerol from Promega (USA). Coomassie blue R-250 were obtained from Bio-Rad (Laboratories GmBH, München, Germany).

\section{Polyphenol mixture: preparation and identification}

Leaves and stems of $P$. barbatus Andrew (a voucher specimen deposited in the Herbarium of this Botanical Garden of the University of Lisbon (LISU: 214625) were boiled in water for $10 \mathrm{~min}$, filtered through Whatman filter paper number 1 , and lyophilized and kept at $-20^{\circ} \mathrm{C}$ until analyzed. The chromatographic analysis was carried out using reverse phase ch atography with a diode array detector (RP-HPLC-DA 2 sescribed in Ref. ${ }^{17}$

\section{Effect of temperature on polyphenol activity} in the presence of protein

RA and polyphenol mixture (PM) at concentration of $0.92 \mathrm{mg} / \mathrm{mL}$ and $4 \mathrm{mg} / \mathrm{mL}$, respectively, were incubated with BSA at $4 \mathrm{mg} / \mathrm{mL}$ in saline phosphate buffer at $\mathrm{pH} 6.4$ $(\mathrm{RA}+\mathrm{BSA})$ and $(\mathrm{PM}+\mathrm{BSA})$. The mixture was incubated at $25^{\circ} \mathrm{C}, 37^{\circ} \mathrm{C}, 70^{\circ} \mathrm{C}$, and $100^{\circ} \mathrm{C}$ for $15 \mathrm{~min}$. RA and $\mathrm{PM}$ were analyzed for AChE inhibition activity assay, antioxidant activity, and native polyacrylamide gel electrophoresis (PAGE). FTIR spectrum of the sample was additionally performed. The assays were carried out in triplicate. The PM was used at the $\mathrm{IC}_{50}$ value for the activity studies. The effect of protein on the bioactivities of the phenolic compounds was studied using BSA at $4 \mathrm{mg} / \mathrm{mL}$, to make the proportion 1:1 used for the FTIR studies. ${ }^{7}$ Aliquots of each test were withdrawn for bioactivity studies and FTIR analysis. Corresponding blanks were also prepared. RA was used at the concentration detected in the plant decoction.

\section{AChE inhibition}

The AChE enzymatic activity was measured using an adaptation of the Ellman's colorimetric method ${ }^{4,18}$ withdrawing $100 \mu \mathrm{L}$ of the $\mathrm{RA}+\mathrm{BSA}$ and $\mathrm{PM}+\mathrm{BSA}$ mixtures incubated at the referred temperatures.

\section{Antioxidant activity}

The antioxidant activity of the aqueous extracts was determined using a slightly modified version of the DPPH method. ${ }^{4}$ Samples of $10 \mu \mathrm{L}$ were withdrawn from RA+BSA and PM+BSA incubated at the temperatures referred.

\section{FTIR spectroscopy analysis and data treatment}

For FTIR analysis, $60 \mu \mathrm{L}$ of the each sample test was dried using $\mathrm{N}_{2}$ current over $\mathrm{CaF}_{2}$ cells and infrared spectra were recorded using a Nicolet ${ }^{\mathrm{TM}}$ FT-IR spectrometer (Thermo Electron Corporations) equipped with a DTGSTEC detector. Sample spectra were recorded by averaging 200 scans in the spectral range of $400-4000 \mathrm{~cm}^{-1}$ at $4 \mathrm{~cm}^{-1}$ resolution. FTIR spectra of the several conditions under analysis were normalized in spectral regions that do not show any absorbance from the protein and the extracts $\left(1800 \mathrm{~cm}^{-1}\right)$. A similar approach was used for the controls, $\mathrm{PM}$, and RA alone. A spectrum of water vapor was also recorded. The OMNIC program was used for the acquisition and processing of the FTIR spectra such as the subtraction of the water vapor interference. Each replicate was subtracted from the herbal infusion control FTIR spectrum. To each subtracted replicate, a Gaussian curve was fitted and an average spectrum was obtained using MATLAB software.

\section{Native PAGE analysis}

Native PAGE for all the tested conditions were carried out as described elsewhere, ${ }^{19}$ stained for protein with Coomassie Brilliant Blue binding dye. ${ }^{19}$ Protein bands were detected using ImageQuant LAS 500 from GE Healthcare Life Sciences ${ }^{\circledR}$ and analyzed with ImageJ software. The protein quantification in gels was performed with a calibration curve obtained after loading the gel with different BSA concentrations. 


\section{Statistical analysis}

The software used was Microsoft ${ }^{\circledR}$ Excel 2013, and the results are expressed as means \pm standard deviations, three replicates for each experiment. Additional analysis of variance was performed at a probability level of $\alpha=0.05 .^{20}$

\section{RESULTS AND DISCUSSION}

\section{Biological activity of $R A$ and $P M$ containing $R A$} in the presence of proteins

To evaluate the bioactivity of RA, either alone or in a mixture of phenolic compounds after being consumed as a medicinal drink, RA and the PM containing RA prepared a decoction of $P$. barbatus was used (Fig. 1). The HPLL DAD analysis of the decoction from $P$. barbatus leaves and stems showed that this aqueous extract is a PM mostly constituted by RA (Fig. 1), as have been reported previously. ${ }^{4}$ In the current study, the RA and PM AChE inhibitory capacity was determined using also BSA as a modulator of compounds bioactivity. The enzyme inhibitory capacity of RA in the presence of BSA (RA+BSA) decreased $58 \%$

F2 (significant at $\alpha=0.05$ ) (Fig. 2a). To evaluate what might happen with the phenolic mixture, the same study was conducted using PM and PM+BSA (Fig. 2b). The inhibitory activity of PM decreased significantly $(\alpha=0.05)$ in the presence of $\mathrm{BSA}(\mathrm{PM}+\mathrm{BSA})$. The inhibition decreased from $20 \%\left(T=25^{\circ} \mathrm{C}\right)$ to $47 \%\left(T=70^{\circ} \mathrm{C}\right)$ in the presence of BSA and the increase in temperature. This means that the $\mathrm{IC}_{50}$ value, previously determined in the absence of BSA, was only able to reduce the enzyme activity by $40 \%$ and $28 \%$ at $25^{\circ} \mathrm{C}$ and $70^{\circ} \mathrm{C}$, respectively. These results of enzyme inhibition by polyphenols in the presence of BSA showed that the compounds capacity to inhibit AChE decreased with increasing temperatures, leading to higher AChE activity. The increase in temperature raises this effect as the inhibitory capacity was reduced. This suggested that the temperature was causing changes in BSA structure that induced a stronger binding of the polyphenolic compounds to the protein, preventing its binding to the $\mathrm{AChE}$ active site. The effect of temperature on PM was analyzed by FTIR and the

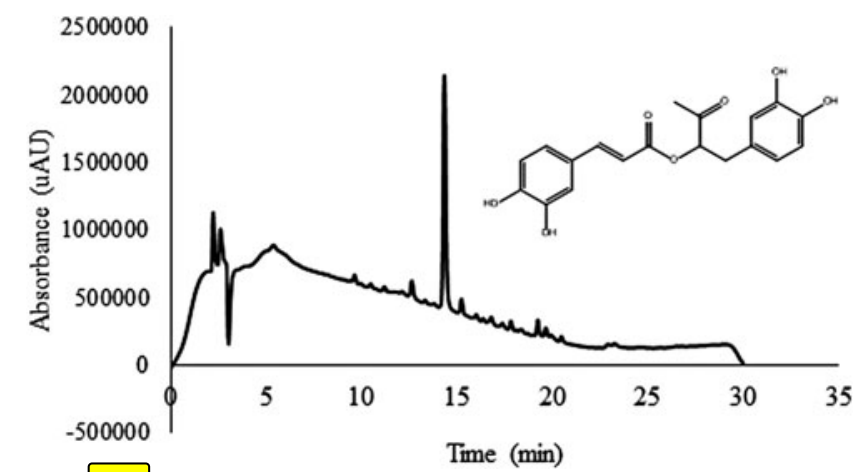

AU13 FIG. 2 IPLC-DAD analysis of RA containing mixture obtained through infusion of Plectranthus barbatus, showing RA structure. $\mathrm{RA}$, rosmarinic acid. spectrum subtracted from the BSA+PM, so the changes detected can be correlated with secondary protein changes.

The antioxidant activity of RA in the absence and presence of BSA (RA+BSA) is presented in Figure 2c. An increase in the antioxidant activity of RA is noticed in the presence of BSA (significant at $\alpha=0.05$ ). The effect on the PM seems also to indicate an increase in this activity in the presence of BSA (Fig. 2d). However, the effect of proteins on the polyphenols antioxidant activity is still a matter of discussion. Some studies indicate that the antioxidant capacity can be changed in the presence of proteins, ${ }^{20}$ while others show that its value is kept constant. ${ }^{2}$ These differences in the behavior of polyphenols toward AChE and antioxidant activities suggested that the binding of polyphenols to BSA prevented them from interacting with the AChE active site, while their capacity to scavenge free radicals (DPPH test) did not change. Binding of several polyphenols to BSA has already been reported, ${ }^{12}$ for example, quercetin binds to BSA with a binding constant that decreases with the temperature, suggesting that temperature diminishes the binding between the polyphenol and the protein. ${ }^{12}$ However, this fact was neither observed in the current study with the PM under evaluation nor with RA. On the contrary, it was seen that polyphenols (RA) inhibition of AChE activity decreased in the presence of BSA and with increase in temperature, suggesting a stronger interaction between polyphenols and BSA. These observations are supported by a previous work showing that the binding of RA to HSA is stronger with the increase in temperature, ${ }^{8}$ and therefore, this binding may explain why the RA containing extract decreases its AChE inhibitory capacity in the presence of protein and at higher temperatures. Although the binding affinity of phenolic compounds, including RA, to BSA have a low-binding constant, ${ }^{23}$ it seems to be sufficient to prevent the freedom of movement of polyphenols to get inside the AChE enzyme active site to exert its inhibitory activity. However, this BSA-phenolic compound binding did not affect the capacity of these compounds to scavenge free radicals in protein presence. During the protein incubation with RA and PM, the formation of a precipitate was seen, at higher temperatures. It might be possible that the BSA precipitation could drag the polyphenols, but the antioxidant activity of the supernatant would decrease, and this never occurred. Binding of RA and PM to BSA was further investigated using FTIR spectroscopy and native PAGE.

Effect of temperature, AR and PM on BSA: FTIR $\Omega$ analysis and native PAGE

FTIR studies. The above mentioned result of BSA on the biological activity of phenolic compounds led to the study of the effect of RA and PM on the BSA secondary structure, at different temperatures, using FTIR spectroscopy. FTIR spectra of BSA, RA+BSA and PM+BSA were obtained. These samples were precisely those from which the enzymatic and antioxidant activity were determined. Analyzing the FTIR spectra of the control BSA at 1800$1400 \mathrm{~cm}^{-1}$, at different incubation temperatures (Fig. 3a, $\langle\mathrm{F} 3$ 

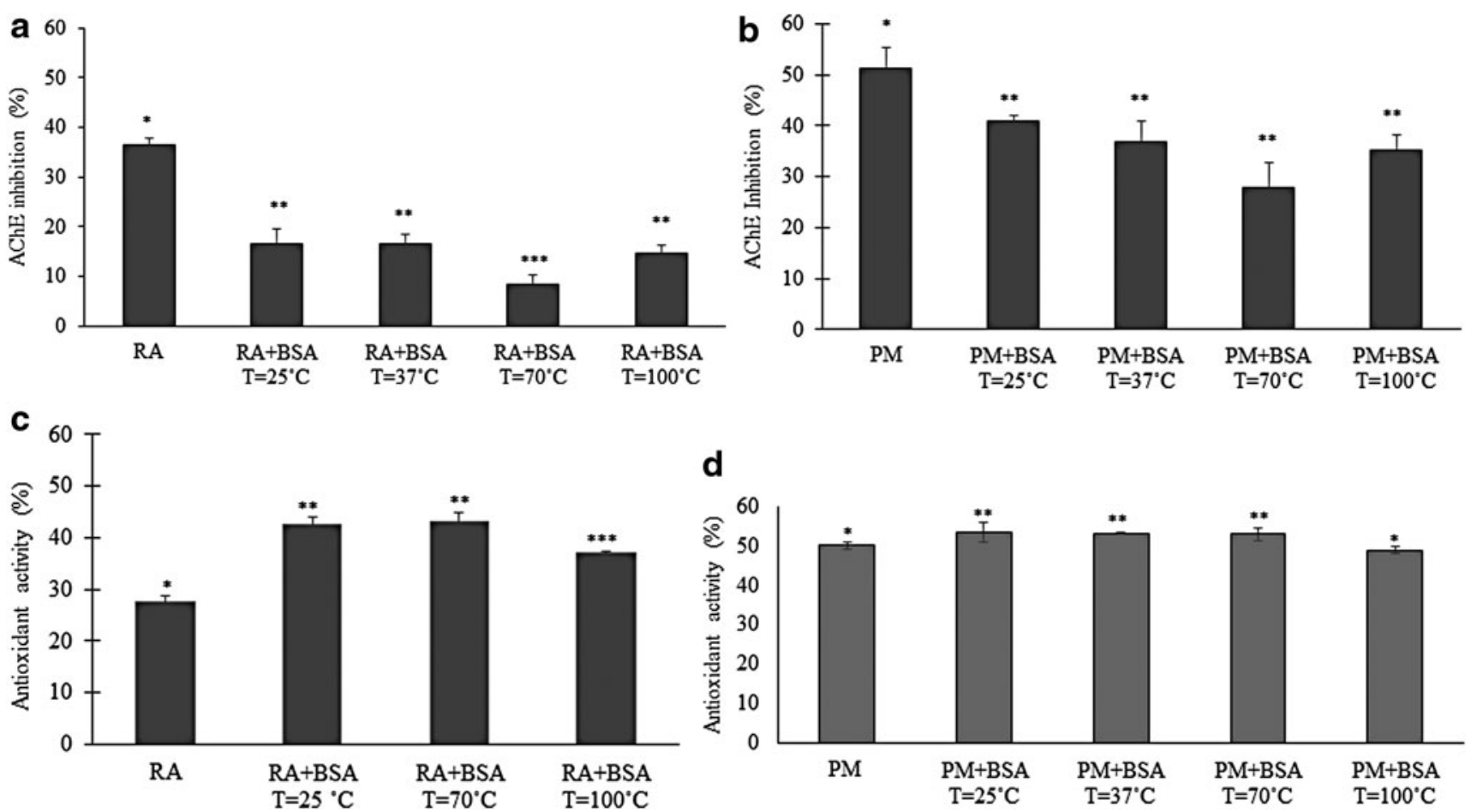

AU14

FIG. 2. Bioactivity of RA and PM containing RA (PM) in the absence and in the presence of BSA: (a) AChE inhibitory activity of RA and RA+BSA, (b) AChE inhibitory activity of PM and PM+BSA, (c) antioxidant activity of RA and RA+BSA, and (d) antioxidant activity of PM and PM+BSA. AChE, acetylcholinesterase; BSA, bovine serum albumin; PM, polyphenol mixture.

solid dark lines), it can be seen that the bands are modified with temperature, even without the presence of the phenolic compounds. The spectrum of BSA, incubated at $25^{\circ} \mathrm{C}$, shows a band with a maximum absorbance around $1655 \mathrm{~cm}^{-1}$, which can be assigned to $\alpha$-helix secondary structure. ${ }^{11}$ The absorbance of this band strongly decreases with temperature, $60 \%, 40 \%$, and $50 \%$ at $37^{\circ} \mathrm{C}, 70^{\circ} \mathrm{C}$, and $100^{\circ} \mathrm{C}$, respectively, indicating a possible decrease in BSA content in solution induced by temperature and protein aggregation. A decrease in the amide II band at $1550 \mathrm{~cm}^{-1}$ was visible which supports a decrease in BSA content in solution. A decrease in amide II band of approximately the same values (as seen with the amide I band), without altering the intensity ratio of amide I/amide II (which is similar in all situations), is noticeable upon raising the temperature from $37^{\circ} \mathrm{C}, 70^{\circ} \mathrm{C}$, and $100^{\circ} \mathrm{C}$, respectively. This corroborates with decreasing protein content in solution with increasing temperature of incubation. The increase in temperature produced protein precipitation that was visible to the naked eye. Although it is difficult to guarantee an homogenous protein distribution in the film obtained for FTIR analysis, the conclusion for a decrease in protein concentration is supported by the following observations: (1) the FTIR absorbance intensity is lower (and the ratio of amide I/amide II remains constant); (2) protein precipitation was observed when the protein in the solution was heated, indicating loss of protein from solution; and (3) FTIR analysis was carried out on an aliquot of clear solution, free of precipitates. With the increasing temperature, the appearance of a shoulder in the amide I band around $1624 \mathrm{~cm}^{-1}$ is also noticeable, often assigned to intermolecular $\beta$-sheet content, ${ }^{11}$ mainly for $70^{\circ} \mathrm{C}$ and $100^{\circ} \mathrm{C}$. The ratio of the absorbance corresponding to secondary structural features of $\beta$-sheet $\left(1624 \mathrm{~cm}^{-1}\right)$ and $\alpha$-helix $\left(1655 \mathrm{~cm}^{-1}\right)$ was calculated. The value of this ratio $(\beta$-sheet $/ \alpha$-helix) showed a steady increase with temperature for BSA control (black bars), with a positive correlation $(r=0.997)$ (Fig. 3b). When analyzing FTIR spectra of BSA incubated with RA (RA+BSA) (Fig. 3a, dotted lines), a protective effect was evident when compared with control BSA (Fig. 3a, solid lines). In fact, the ratio between the $\beta$ sheet $/ \alpha$-helix absorptions denotes a protective effect against temperature-induced protein denaturation by RA (Fig. 3b). In this case, the correlation between the ratio increasing with the temperature is 0.679 , which indicates a deviation from linearity, since there is a stabilization of this ratio in the protein denaturation in the presence of RA.

Analyzing the FTIR spectra of BSA incubated with PM (PM+BSA) (Fig. 3a, dashed lines), it is noticeable that these spectra present overall higher values of absorption than control BSA spectra, except for $25^{\circ} \mathrm{C}$. The fact that absorbance at $25^{\circ} \mathrm{C}$ is similar for both, BSA alone and PM+BSA, rules out the possibility that the increase in absorption at higher temperatures for PM+BSA, compared to BSA alone, is due to absorbance contributions from the extracts. The extract was used as a control to obtain these spectra of PM+BSA. These subtractions can be done, because the extract does not have strong absorption in the region of protein bands. The presence of the extract apparently 


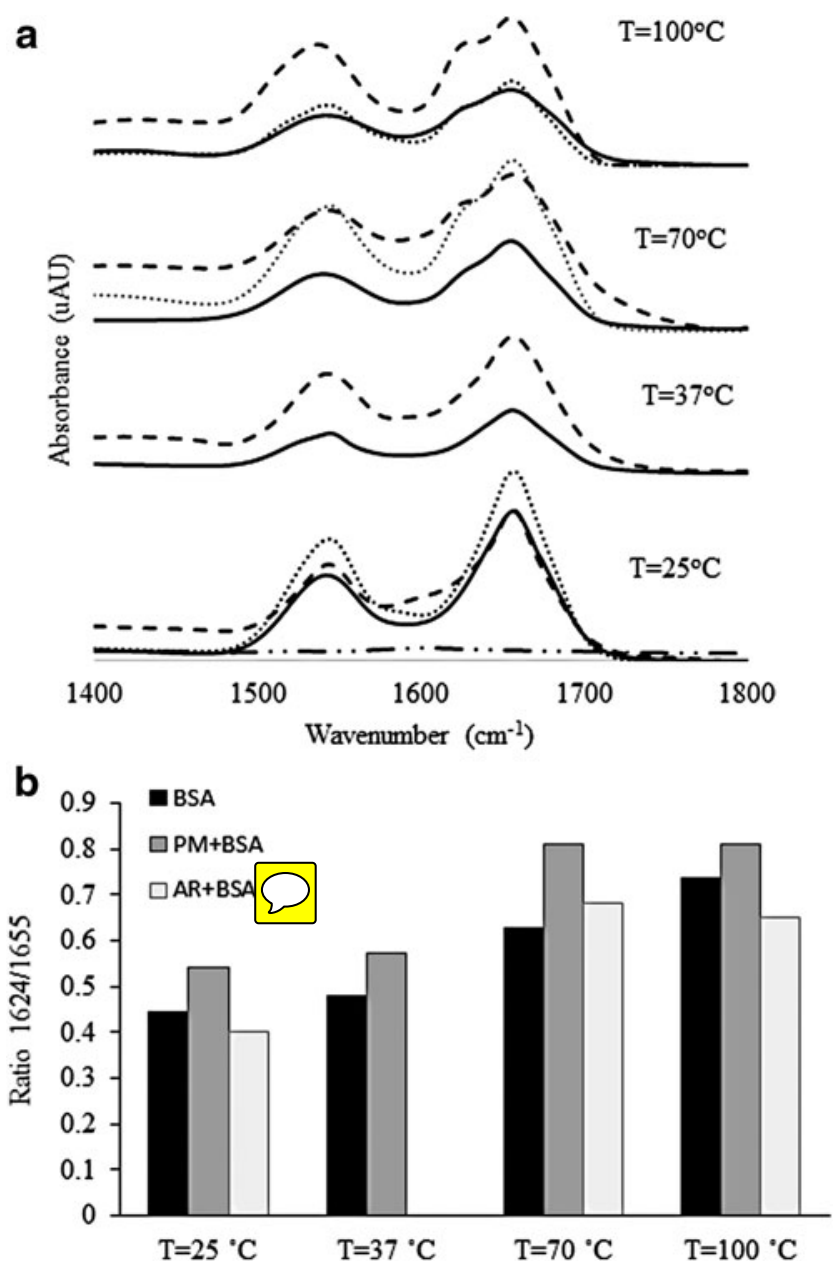

FIG. 3. Analysis of BSA secondary structure in the absence and in the presence of RA, PM at different temperatures: (a) FTIR spectrum of (_) BSA alone; (—) PM+BSA; (...) RA+BSA; (.....) PM; and AU15 (b) Effect of incubation temperature on $\beta$-sheet/ $\alpha$-helix ratios. FTIR, Fourier transform infrared spectroscopy.

increased the amount of BSA remaining in solution comparatively to BSA control. This effect can be associated to the phenolic compounds present in the herbal decoction protecting against protein aggregation by heat, as previously reported. ${ }^{24}$ A new arrangement in the BSA secondary structure, with formation of intermolecular $\beta$-sheet, was noticed mainly for $70^{\circ} \mathrm{C}$ and $100^{\circ} \mathrm{C}$ (Fig. 3a, dashed lines), as an increase in temperature seemed to have caused the appearance of a shoulder in the amide I band around $1624 \mathrm{~cm}^{-1}$. This ratio indicates a change in the protein secondary structure, with formation of intermolecular $\beta$ sheet structures with temperature increase. However, the increase between $70^{\circ} \mathrm{C}$ and $100^{\circ} \mathrm{C}$ was not seen when BSA was incubated with PM (PM +BSA) (Fig. 3b). The correlation is 0.847 , lower than that obtained with BSA alone, meaning that the relationship stopped being a linear one.

Overall, these and all the above stated variations can indicate a decrease in BSA protein in solution as a result of aggregation/precipitation of the protein with increasing temperature. In addition, a structural modification occurs on

BSA remaining in solution by the increase in $\beta$-sheet content. Therefore, when in the presence of the PM, BSA remained mostly in the soluble form, despite modifications in its secondary structures mainly due to the increase in preincubation temperature.

The inhibitory activity of RA modulated by the presence of BSA may be explained by the fact that RA interaction with BSA traps it and avoids RA from being free in solution to enter the active site of AChE and inhibit its activity. On the contrary, the antioxidant activity of RA is not affected by the presence of BSA, probably as binding to the protein may stabilize the radicals formed during a redox reaction.

Native PAGE analysis. During the analysis of the effect of herbal decoction at various temperatures, on BSA, it was seen that with increasing temperature, the precipitation of BSA, mainly in control BSA (without PM or RA) occurs. This effect, clearly visible in the test tube, was analyzed by native PAGE for BSA, RA+BSA (Fig. 4a), and PM+BSA (Fig. 4b). In these figures, it is possible to observe that for all the conditions tested, the increase in temperature resulted in a decrease of the intensity and in the number of the bands, for all the left lanes (BSA control) and right lanes (RA+B$\mathrm{SA})$ and $(\mathrm{PM}+\mathrm{BSA})$. At higher temperatures $\left(70^{\circ} \mathrm{C}\right.$ and $100^{\circ} \mathrm{C}$ ), the appearance of new bands on the top of the gel can be due to protein-protein interactions, resulting in

a

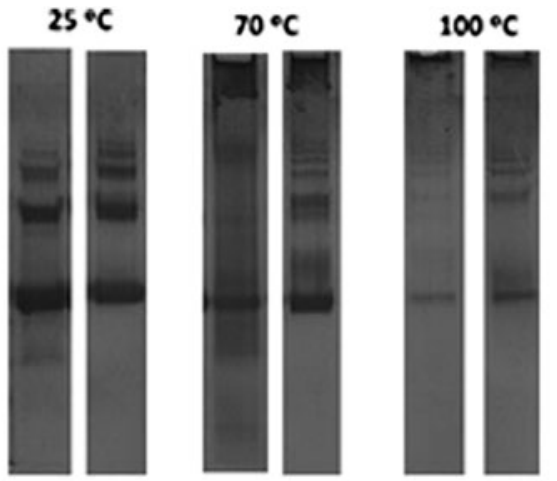

b $25^{\circ} \mathrm{C}$
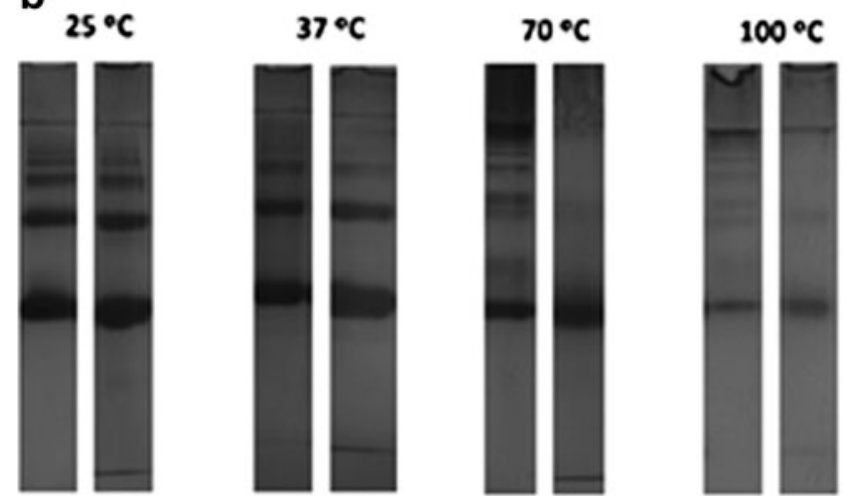

FIG. 4. Native gel electrophoresis at different temperatures: (a) RA+BSA at different temperatures (first lane for each set is BSA alone); (b) PM+BSA at different temperatures (first lane for each set is BSA alone). 
Table 1. Effect of Temperature on Bovine Serum Albumin Concentration in Solution in the Absence and Presence of Rosmarinic Acid and Plectranthus barbatus Extracts (Polyphenol Mixture)

\begin{tabular}{llc}
\hline Temperature $\left({ }^{\circ} \mathrm{C}\right)$ & Sample & Protein \\
\hline 25 & BSA & 3.38 \\
& RA+BSA & 3.71 \\
& PM+BSA & 3.43 \\
37 & BSA & 2.30 \\
& RA+BSA & - \\
& PM+BSA & 2.61 \\
70 & BSA & 2.46 \\
& RA+BSA & 2.96 \\
& PM+BSA & 2.95 \\
100 & BSA & 0.47 \\
& RA+BSA & 1.94 \\
& PM+BSA & 0.66 \\
\hline
\end{tabular}

BSA, bovine serum albumin; PM, polyphenol mixture; RA, rosmarinic acid.

higher molecular weight bands in the gel. The amount of

protein in the gel was quantified (Table 1). A correlation of $0.798,0.712$, and 0.959 is determined for the decrease in protein in solution with the increase in temperature, for $\mathrm{BSA}, \mathrm{RA}+\mathrm{BSA}$, and $\mathrm{PM}+\mathrm{BSA}$, respectively. The presence of RA or PM does not completely prevent BSA precipitation, but more protein is seen in these lanes, meaning that more protein remained in solution. There is a protective effect of 9-312\% in the case of RA and 1-20\% in the case of $\mathrm{PM}$, increasing the protein content in solution. This fact indicates that RA is the main cause of the protection of BSA from precipitating at higher temperatures. These results seem to suggest the binding between the phenolic compounds and the protein. However, the characteristics of the binding between protein and phenolic compounds may depend on the nature of the intervening molecules, namely protein and phenolic features. Therefore, different results can be obtained with BSA and diverse phenolic compounds. ${ }^{25}$ Protein binding to the phenolic compounds is evident in the FTIR experiments and also in native PAGE analysis, mainly at higher temperatures. These results are in accordance with the results found in Ref. ${ }^{26}$

RA in the presence of proteins shows a decrease in their capacity to act as enzyme inhibitor. The same situation is observed when this polyphenol is in a mixture together with other phenolic compounds. However, its antioxidant activity remains constant or even with a tendency to increase. Modifications in BSA secondary structure with the increase in temperature was not prevented by the presence of polyphenols, but they do have some inhibitory effects on protein aggregation and more protein can remain in solution in the presence of PM compared to BSA alone. Polyphenol binding to BSA prevents the $\mathrm{AChE}$ inhibitors to interact with the enzyme active site. To the best of our knowledge, this is the first report on the effect of proteins on the modulation of the biological activity of phenolic compounds, mainly RA. These results are a significant contribution to the under- standing of how the binding of proteins, at least in the plasma, can impact the activity of phenolic compounds.

\section{ACKNOWLEDGMENTS}

The authors thank Fundação para a Ciência e Tecnologia for financial support: CQB (PEst-OE/QUI/UI0612/2013); BioIsi (UID/MULTI/04046/2013); CESAM (UID/AMB/ 50017), through FCT/MEC National funds, and the cofunding by the FEDER, within the PT2020 Partnership Agreement and Compete 2020.

\section{AUTHOR DISCLOSURE STATEMENT}

No competing financial interests exist.

\section{REFERENCES}

1. Li A, Li S, Zhang YJ, Xu XR, Chen YM, Li HB: Resources and biological activities of natural polyphenols. Nutrients 2014;6: 6020-6047.

2. Saltas D, Pappas CS, Daferera D, Tarantilis PA, Pollissiou MG: Direct determination of rosmarinic acid in Lamiaceae herbs using diffuse reflectance infrared Fourier transform spectroscopy (DRIFTS) and chemometrics. J Agric Food Chem 2013;61:3235-3241.

3. Xu DP, Li Y, Meng X, Zhou T, Zhou Y, Zheng J, Zhang JJ, Li HB: Natural antioxidants in foods and medicinal plants: Extraction, assessment and resources. Int J Mol Sci 2017;18:1-32.

4. Falé PL, Borges C, Madeira PJA, Ascensão L, Araújo MEM, Florêncio MH, Serralheiro MLM: Rosmarinic acid, scutellarein 40-methyl ether 7-O-glucuronide and (16S)-coleon E are the main compounds responsible for the antiacetylcholinesterase and antioxidant activity in herbal tea of Plectranthus barbatus ("falso boldo"). Food Chem 2009;114:798-805.

5. Jung CS, Sang OS, Rong KC, Kyung KY, Hwan SS, Kyeom KJ, Gun PG, Seung-Yeol S, Dong-Hoon S: Perilla frutescens extract ameliorates acetylcholinesterase and trimethyltin chlorideinduced neurotoxicity. J Med Food 2016;19:281-289.

6. Colovic MB, Krstic DZ, Lazarevic-Pasti TD, Bondzic AM, Vasic VM: Acetylcholinesterase inhibitors: Pharmacology and toxicology. Curr Neuropharmacol 2013;11:315-335.

7. Falé PLV, Ascensão L, Serralheiro ML, Haris P: Interaction between Plectranthus barbatus herbal tea components and acetylcholinesterase: Binding and activity studies. Food Funct 2012;3:1176-1184.

8. Falé PL, Madeira PJA, Florêncio MH, Ascensão L, Serralheiro ML: Function of Plectranthus barbatus herbal tea as neuronal acetylcholinesterase inhibitor. Food Funct 2011;2:130-136.

9. Carter DC, He X, Munson SH, Twigg PD, Gernert KM, Broom MB, Miller TY: Three-dimensional structure of human serum albumin. Science 1989;244:1195-1198.

10. Majorek KA, Porebski PJ, Dayal A, Zimmerman MD, Jablonska K, Stewart AJ, Chruszcz M, Minor W: Structural and immunologic characterization of bovine, horse, and rabbit serum albumins. Mol Immunol 2012;52:174-182.

11. Haris PI, Severcan F: FTIR spectroscopic characterization of protein structure in aqueous and non-aqueous media. J Mol Catal B Enzym 1999;7:207-221.

12. Rawel HM, Meidtner K, Kroll J: Binding of selected phenolic compounds to proteins. J Agric Food Chem 2005;53:4228-4235.

13. Barth A: Infrared spectroscopy of proteins-review. Biochim Biophys Acta 2007;1767:1073-1101. 
14. Murphy BM, D'Antonio J, Manning MC, Al-Azzam W: Use of the amide II infrared band of proteins for secondary structure determination and comparability of higher order structure. Curr Pharm Biotechnol 2014;15:880-889.

15. Koichi M, Tomida M: Heat-induced secondary structure and conformation change of bovine serum albumin investigated by Fourier transform infrared spectroscopy. Biochem 2004;43: 11526-11532.

16. Bouhekka A, Bürgi T: In situ ATR-IR spectroscopy study of adsorbed protein: Visible light denaturation of bovine serum albumin on $\mathrm{TiO}_{2}$. Appl Surf Sci 2012;261:369-374.

17. Falé PL, Ferreira C, Rodrigues AM, Cleto P, Amorim PJ, Florêncio MH, Frazão FN, Serralheiro ML: Antioxidant and antiAcetylcholinesterase activity of commercially available medicinal infusions after in vitro gastrointestinal digestion. $J$ Med Plants Res 2013;7:1370-1378.

18. Ingkaninan $\mathrm{K}$, Temkitthawon $\mathrm{P}$, Chuenchon $\mathrm{K}$, Yuyaem $\mathrm{T}$, Thongnoi W: Screening for acetylcholinesterase inhibitory activity in plants used in Thai traditional rejuvenating and neurotonic remedies. J Ethnopharmacol 2003;89:261-264.

19. Muratsubaki H, Satake K, Yamamoto Y, Enomoto K: Detection of serum proteins by native polyacrylamide gel electrophoresis using Blue Sepharose CL-6B-containing stacking gels. Anal Biochem 2002;307:337-340.
20. Lison L: Statistique Appliqué à la Biologie Experimentel. Gauthier-Villars, Paris, 1968, pp. 65-74.

21. Brudzynski K, Maldonado-Alvarez L: Polyphenol-protein complexes and their consequences for the redox activity, structure and function of honey. A current view and new hypothesis-A review. Pol J Food Nutr Sci 2015;65:71-80.

22. Trigueros L, Wojdyło A, Sendra E: Antioxidant activity and protein-polyphenol interactions in a pomegranate (Punica granatum L.) yogurt. J Agric Food Chem 2014;62:6417-6425.

23. Skrt M, Benedik E, Podlipnik C, Ulrih NP: Interactions of different polyphenols with bovine serum albumin using fluorescence quenching and molecular docking. Food Chem 2012;135: 2418-2424.

24. Ali H, Alli I, Ismail A, Kermasha S: Protein-phenolic interactions in food. Eurasian J Anal Chem 2012;7:123-133.

25. Prigent SVE, Gruppen H, Visser AJWG, van Koningsveld GA, de Jong H, Voragen AGJ: Effects of non-covalent interactions with 5-O-caffeoylquinic acid (chlorogenic acid) on the heat denaturation and solubility of globular proteins. J Agric Food Chem 2003;51:5088-5095.

26. Murayama K, Tomida M: Heat-induced secondary structure and conformation change of bovine serum albumin investigated by Fourier transform infrared spectroscopy. Biochem 2004;43: 11526-11532. 


\section{AUTHOR QUERY FOR JMF-2017-0086-VER9-BRITO_1P}

AU1: Please review all authors' surnames for accurate indexing citation

AU2: Please provide the affiliations in Englis

AU3: Please provide the department in the affiliations " 1,3 , and 5 ( 2)

AU4: Please confirm the corresponding author's name andrace

AU5: Please provide the corresponding author address in 1

AU6: Please check the hierarchy of heading levels in the article.

AU7: The Publisher requests for readability that no paragraph exceeds 15 typeset lines. Please check for long paragraphs and divide where needed.

AU8: Please shegk the expansion "reverse phase chromatography with a diode array detector" of the acronym "RP-HPLCDAD.'

AU9: Please expand "AR.

AU10: In "Ref. 20," please provide the English translat

AU11: Please cite Ref. " 21 " in the text. $\bigcirc$

AU12: Please cite Ref. "22" in the tevt

AU13: Please expand "HPLC-DAD. 2

AU14: Asterisks are given in the artwork of Figure 2, but not described in the figure legend of the same. Please check.

AU15: Please define "AR. $P$ 